\title{
Therapeutic Plasma Exchange: For Cancer Patients
}

\author{
Yuru Hu, Hanshan Yang, Shaozhi Fu D, Jingbo Wu \\ Department of Oncology, The Affiliated Hospital of Southwest Medical University, Luzhou, 646000, People's Republic of China
}

Correspondence: Jingbo Wu; Shaozhi Fu, Department of Oncology, The Affiliated Hospital of Southwest Medical University, Luzhou, 646000, People's Republic of China, Tel+8613980257/36, Email wjb6147@I63.com; shaozhifu5I3@I63.com

\begin{abstract}
Therapeutic plasma exchange is used as a trial method for the treatment of cancer patients. Therapeutic plasma exchange uses in vitro technology to remove pathogenic factors in the plasma, returning the replacement and remaining components to the patient to facilitate cure. In the effort to explore new methods of cancer treatment, the introduction of therapeutic plasma exchange brings new hope for cancer treatment; however, the current evidence supporting therapeutic plasma exchange is controversial, and most of the evidence comes from observational studies, lacking large prospective randomized trials. Therefore, this review attempts to focus on the main indications of therapeutic plasma exchange for the treatment of tumors and their complications, including hematological tumors (multiple myeloma cast nephropathy and hyperviscosity syndrome), nervous system tumors (myasthenia gravis associated with thymoma, paraneoplastic neurological syndrome, Lambert-Eaton myasthenia syndrome, and anti-N-methyl-D-aspartate receptor encephalitis), overdose of chemotherapy drugs. In addition, the issues of side-effects and safety in the use of therapeutic plasma exchange are also discussed. However, well-designed prospective trials are needed to better define the role of therapeutic plasma exchange in cancer.
\end{abstract}

Keywords: therapeutic plasma exchange, plasma exchange, double-filtration plasmapheresis, plasma adsorption, indications, complications

\section{Introduction}

Cancer is becoming the second most common cause of death in the world. Traditional treatment methods include surgery, chemotherapy, radiotherapy, and hormone therapy, as well as various combination therapies. ${ }^{1}$ Modern treatment approaches are multi-model, including emerging molecular and targeted therapies, ${ }^{2}$ but these methods have limited effectiveness in improving survival. New ways to slow the progression of cancer and even to cure it are being sought. Therapeutic plasma exchange (TPE) therapy is one such way. Plasma replacement therapy has been in development for more than 50 years and has become a common and relatively safe treatment. ${ }^{3,4}$ It can be used as a treatment of first choice in some diseases such as thrombotic thrombocytopenic purpura, ${ }^{5,6}$ but is usually used as an adjunct to treatment.

TPE is a blood component apheresis technology used mainly for symptomatic treatment; it is used to remove pathological plasma while supplementing a certain amount of normal plasma or solution to treat patients with cancer and related complications. ${ }^{7}$ TPE can eliminate macromolecular proteins and antibodies, and it is precisely because of this immunological property that it is useful in the treatment of patients with malignant tumors. ${ }^{8}$

TPE therapy plays an important role in the treatment of a variety of tumors, such as multiple myeloma and Waldenström macroglobulinemia, and can also be used to eliminate paraneoplastic syndromes and excessive levels of chemotherapeutic drugs. ${ }^{9-11}$ The TPE process involves removing or reducing the concentration of harmful substances in the plasma. First, the whole blood is passed through an external filter to separate the plasma and cellular components. After the removal of part of the harmful or pathological components in the plasma, the cellular components and replacement fluid are mixed on returning the remaining plasma to the body. The most commonly used TPE types are plasma exchange (PE), double-filtered plasmapheresis (DFPP), and plasma adsorption (PA). ${ }^{12}$

This review briefly summarizes these three methods, examines the application of TPE in tumor treatment to understand its therapeutic effects, and speculates that TPE alone or in combination with other therapies can replace or 
Table I The Different Ways of Therapeutic Plasma Exchange

\begin{tabular}{|c|c|c|c|c|c|}
\hline Modalities & $\begin{array}{l}\text { The Molecular Weight of the } \\
\text { Removed Component }\end{array}$ & Indication & Alternative Solution & Efficiency & Specificity \\
\hline Plasma exchange (PE) & $\begin{array}{l}\text { Small and large molecules no larger } \\
\text { than a few million Daltons }\end{array}$ & $\begin{array}{l}\text { Thrombotic microangiopathy (TMA) } \\
\text {-Acute liver failure } \\
\text { Diseases of the nervous system } \\
\text { Myeloma cast nephropathy }\end{array}$ & $\begin{array}{l}\text { - Fresh frozen plasma } \\
\text { (FFP) } \\
\text { - 4-6\% Albumin } \\
\text { solution }\end{array}$ & High & Low \\
\hline $\begin{array}{l}\text { Double-filtration } \\
\text { plasmapheresis (DFPP) }\end{array}$ & A relatively large molecule in plasma & Hyperviscosity syndrome (HVS) & $\begin{array}{l}\text { Usually a solution of } \\
\text { albumin }\end{array}$ & Middle & Middle \\
\hline Plasma adsorption (PA) & $\begin{array}{l}\text { Selective adsorption, such as } \\
\text { autoantibodies, immune complexes, etc }\end{array}$ & $\begin{array}{l}\text { Myasthenia gravis (MG) } \\
\text { Guillain Barre syndrome (GBS) }\end{array}$ & - & Low & High \\
\hline
\end{tabular}

improve current tumor treatments. In addition, the side-effects of TPE have also been included in the scope of this review.

\section{TPE Modalities}

The most commonly used TPE methods include PE, DFPP, PA. ${ }^{13}$ Each of these three methods has advantages and disadvantages, depending on the principle and specificity of the removal of the target substance. Table 1 illustrates the differences in molecular weight of the removed components, indications, replacement solutions, and removal efficiency and the specificity of the three methods.

\section{Plasma Exchange (PE)}

After the introduction of DFPP, PE was also known as single-filter plasmapheresis (SFPP). ${ }^{14}$ It is a method of treating isolated blood and replenishing a replacement solution of the corresponding component, which is primarily used to eliminate pathogenic material and provide the necessary ingredients. ${ }^{12}$ The PE principle is shown in Figure 1.

The sieving coefficient of PE for most plasma proteins is $0.9-1.0$, and the selectivity is low, so both large and small molecules can be filtered out. ${ }^{15}$ In addition to removing pathological solutes, PE may also have immunomodulatory effects, such as removing immune-related molecules in the circulation and enhancing the sensitivity of cells to immunosuppressive agents. ${ }^{16}$

Although desirable properties of PE replacement fluids have been proposed, it is difficult for the actual replacement fluids to meet these standards. ${ }^{12}$ For this reason, in practical applications, fresh frozen plasma (FFP) or a 4-5\% human albumin solution that meets the patient's pathophysiological conditions is often used as an alternative liquid. ${ }^{17}$ In addition, the choice of vascular access is related to the physiological condition of the patient as well as the frequency and velocity of the PE.

\section{Double-Filtration Plasmapheresis (DFPP)}

DFPP does not remove all plasma but semi-selectively removes high molecular weight components such as immunoglobulins, immune complexes, and lipoproteins in the plasma. ${ }^{18}$ Therefore, DFPP selectively removes macromolecules while reducing the use of replacement fluids.

As shown in Figure 2, DFPP requires the passage of the patient's blood through two filters. ${ }^{19}$ The two filters have different pore sizes. The first filter is the same as the plasma separator in PE and is used to separate the tangible components of blood and plasma. The second filter is the plasma fractionator, which filters the plasma components according to their molecular weights. The concentrated plasma portion containing relatively high molecular weight proteins (such as immunoglobulins) is discarded while the plasma rich in albumin is filtered and returned to the patient with the required volume of replacement fluid. 


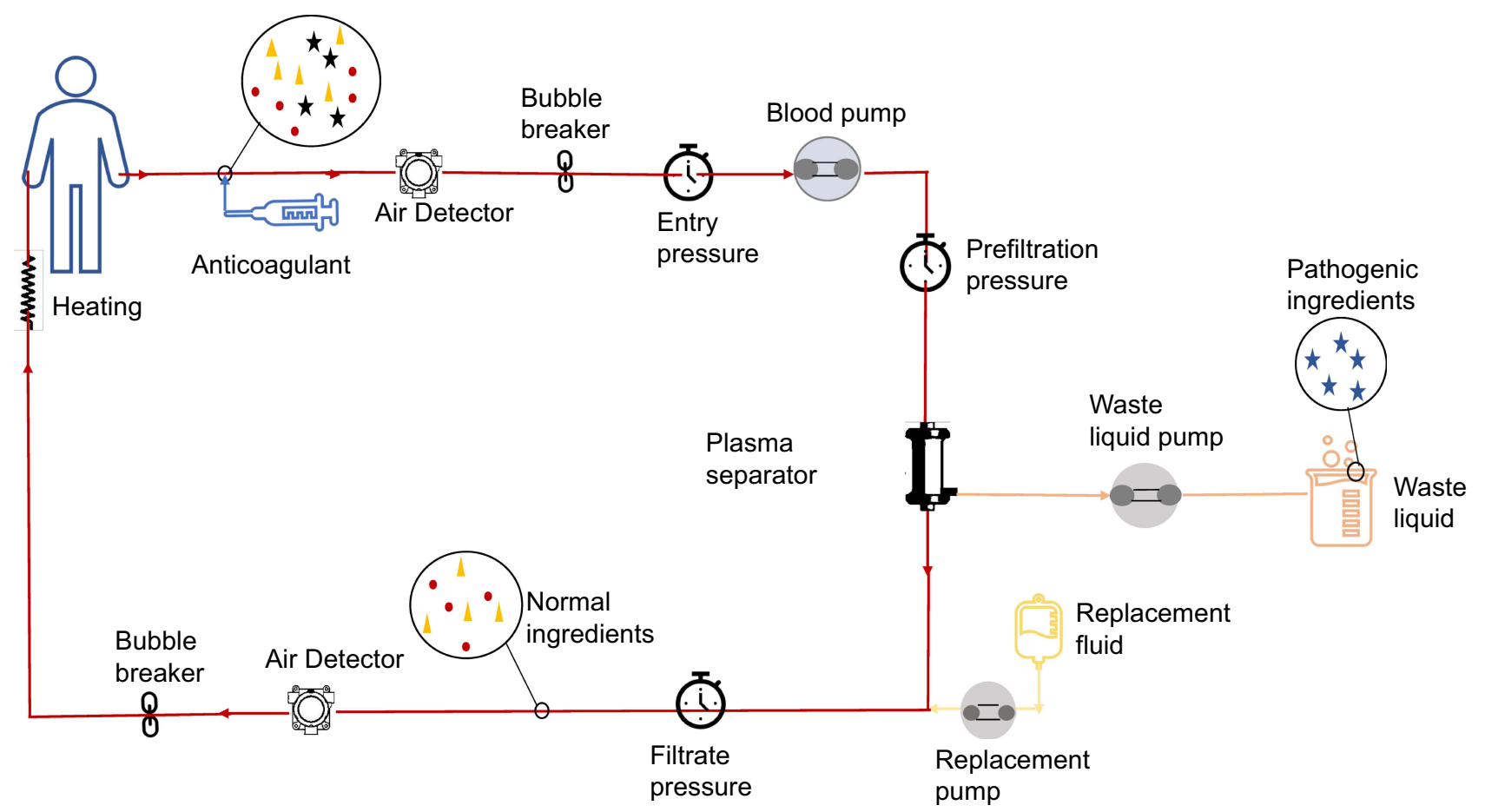

Figure I The principle of plasma exchange (PE). The blood is separated from the body, processed and then passed through a single plasma separator. The filtered blood components are returned to the body together with the replacement fluid.

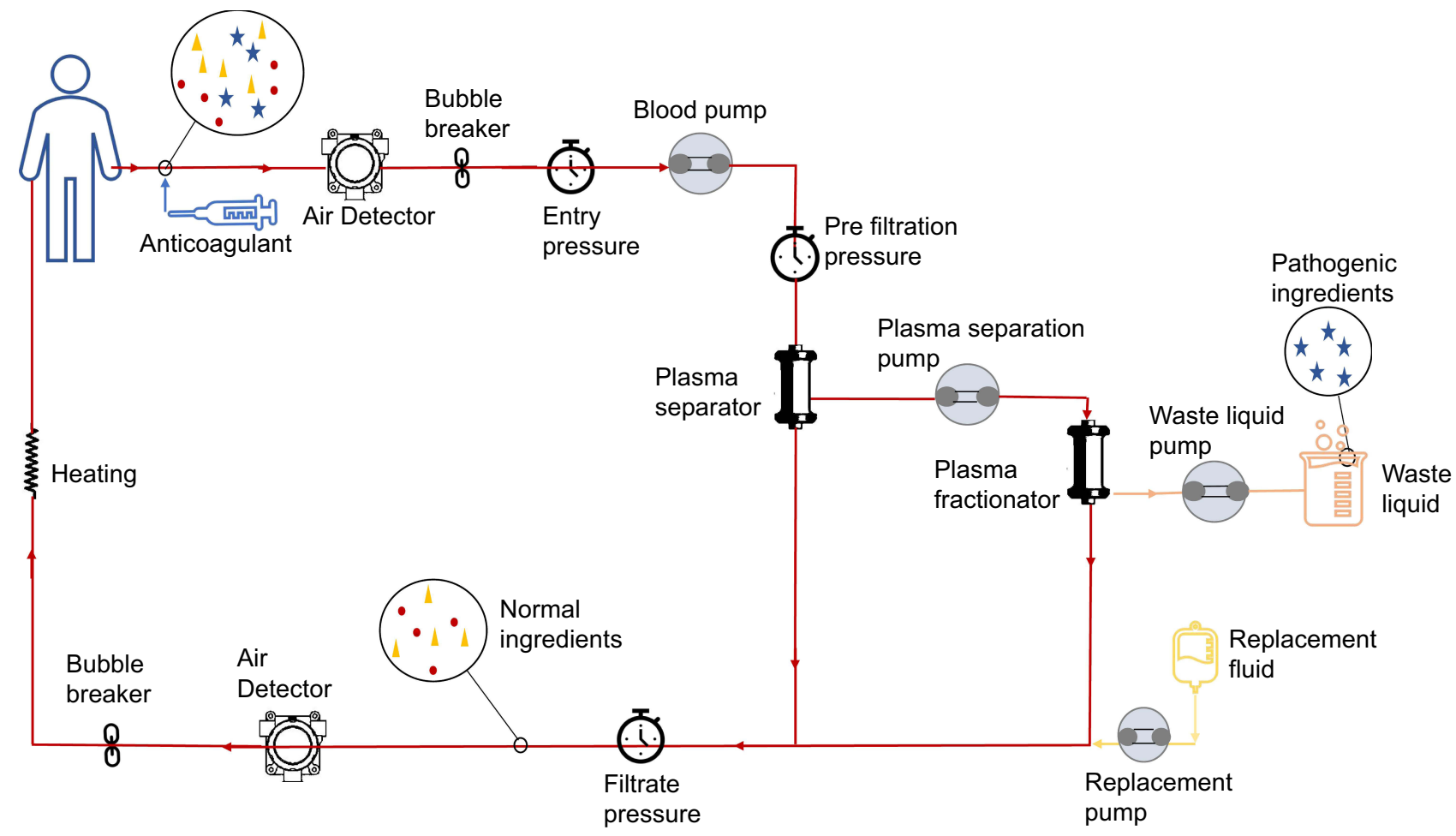

Figure 2 The principle of double filtration plasmapheresis (DFPP). The blood passed through the plasma separator and then passed through the plasma fractionator, and the filtered components were also returned to the human body after being combined with the replacement solution. 
Because DFPP can greatly reduce the levels of autoantibodies in the circulation, it has obvious efficacy in reducing the titers of autoantibodies and immunoglobulins. ${ }^{20}$ In addition, DFPP may also have the ability to regulate the function of regulatory $\mathrm{T}$ cells (Tregs) and increase the proportion of these cells in the plasma. ${ }^{21}$

\section{Plasma Adsorption (PA)}

$\mathrm{PA}$ is a process of selective adsorption and removal of pathological substances using adsorbents. ${ }^{22}$ It does not require the addition of replacement fluids, thus minimizing the loss of useful plasma proteins and avoiding the possibility of viral infections or allergic reactions to albumin, Figure 3.

There are two types of PA adsorbents, biological and non-biological adsorbents. ${ }^{23}$ The affinity of biosorbents is higher than that of non-biosorbents because biosorbents rely on biological reactions for adsorption while non-biosorbents rely on physical and chemical binding forces. However, biosorbents are difficult to sterilize and are biochemically unstable whereas non-biosorbents are not only stable but also suitable for sterilization.

PA is widely used in nervous system diseases, ${ }^{24}$ including Guillain-Barre syndrome (GBS) ${ }^{25}$ chronic inflammatory demyelinating neuropathy (CIDP), ${ }^{26}$ multiple sclerosis (MS), ${ }^{27}$ neuromyelitis optica (NMO) ${ }^{28}$ rheumatic diseases (such as lupus nephritis), ${ }^{29}$ and other refractory diseases. In addition to eliminating pathogenic agents, PA is thought to result in alterations in the balance of cytokines associated with autoimmunity by clearing antibodies in large quantities, such as stimulating the upregulation of anti-inflammatory cytokines (such as interleukin - 10 (IL-10)) and reducing proinflammatory factors (for example, interleukin - 18 (IL-18) and interleukin - 17 (IL-17)). ${ }^{30}$

\section{Application of TPE in Tumor Therapy}

Due to its ability to eliminate pathological molecules, TPE has played a major role in the treatment of a variety of tumors including hematological and neurological tumors. Table 2 shows the ASFA staging and classification of the diseases discussed in this review. ${ }^{31}$

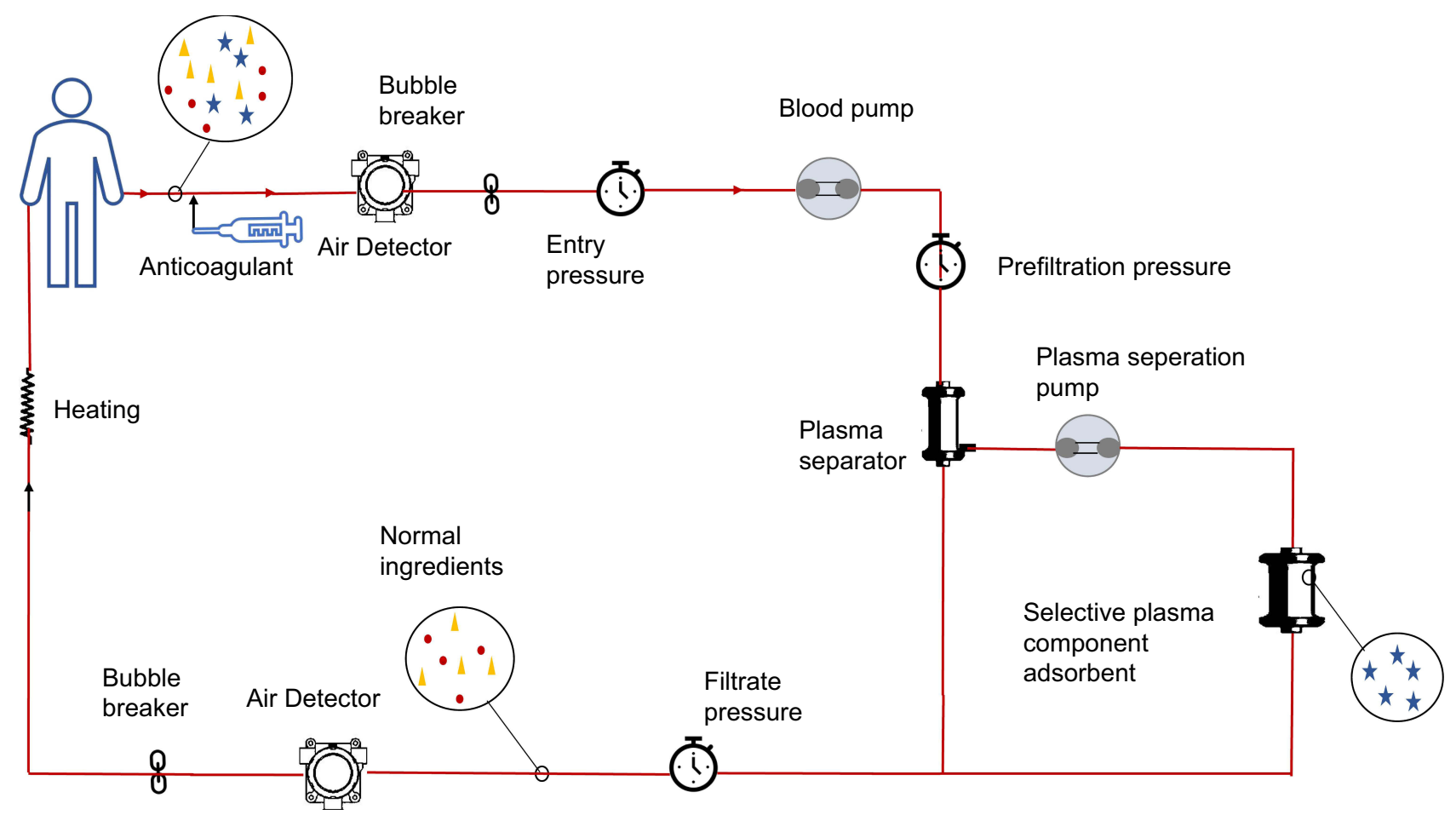

Figure 3 The principle of plasma adsorption (PA). Blood that has gone through a plasma separator is washed out of the blood with selective adsorbents and returned directly to the body. 
Table 2 Indications for TPE in Patients with Cancer

\begin{tabular}{|l|l|l|l|}
\hline Disease & Indication & Category & Grade $^{\mathbf{a}}$ \\
\hline MCS & & II & 2B \\
HVS & Symptomatic & I & IB \\
& Prophylaxis for rituximab & I & IC \\
MG & Acute, short-term treatment & I & IB \\
& Long-term treatment & I & $2 B$ \\
PNS & & III & $2 C$ \\
LEMS & & II & $2 C$ \\
NMDAR & & I & IC \\
\hline
\end{tabular}

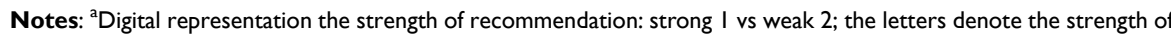
evidence support, A, B, C respectively represents high, middle and low evidence support.

\section{Hematological Tumors Myeloma Cast Nephropathy}

Multiple myeloma (MM) is a malignant disease of plasma cells characterized by abnormal myeloid plasma cell proliferation and the development of monoclonal or excessive free light chains (FLCs, or M proteins). More than 50\% of patients with multiple myeloma develop renal insufficiency and the prognosis of these patients is closely related to the reversibility of the renal failure. ${ }^{32,33}$ Cast nephropathy is a potentially reversible cause of renal failure. It is usually caused by increased renal tubular filtration of FLCs. ${ }^{34}$

Supportive treatment for multiple myeloma is the most common indication of TPE in hematology. In addition to correcting hypercalcemia and immediate reduction in the blood volume, ${ }^{35}$ TPE also plays an important preventive role in the management of multiple myeloma patients. Removal of the FLCs and recovery of renal function are key to the treatment of renal failure caused by cast nephropathy. TPE therapy has been shown to reduce renal damage caused by FLCs, reduce tube formation, and prevent the progression of renal failure in patients with myeloma. It was first used in 1976 to treat acute renal failure caused by multiple myeloma. ${ }^{36}$ However, three randomized controlled trials on the efficacy of TPE in multiple myeloma cast nephropathy have provided conflicting results. These three randomized controlled trials studied the effect of PE on cast nephropathy. Two of the trials involved 29 and 21 participants, but produced conflicting results. ${ }^{37,38}$ A subsequent relatively large randomized controlled trial (97 participants) conducted by Clark et al did not find a substantial advantage of TPE in multiple myeloma. ${ }^{39}$

Leung et al demonstrated that TPE restored renal function solely by reducing the levels of circulating light chains in patients with biopsy-confirmed cast nephropathy. ${ }^{40}$ It is worth noting that none of these three randomized controlled trials confirmed tubular nephropathy by biopsy and nor measured the FLC levels. Since the most important factor in determining survival continues to be a patient's response to chemotherapy, renal biopsy is recommended to determine whether each patient should be treated with TPE in combination with chemotherapy. ${ }^{41}$ TPE does not reduce the tumor burden and does not have a clear benefit in extending survival, so it is only recommended for specific subgroups such as patients with very high circulating light chain levels and patients with severe renal failure and is not recommended for the routine treatment of multiple myeloma. ${ }^{42,43}$ At present, it is accepted that concurrent chemotherapy and TPE can improve the prognosis before the blood FLC level is significantly reduced. The improved outcomes and survival of patients with cast nephropathy were significantly associated with reduced FLCs. Although it remains controversial whether TPE alters renal outcomes at present, it is well established that TPE significantly reduces FLCs and that the decrease is more profound as the number of TPE increases. This allows TPE to improve kidney function when combined with chemotherapy, thus prolonging the patient's survival. ${ }^{44,45}$ Proteasome inhibitors improve cast nephropathy through antiinflammation of renal interstitium and thus have an extremely important role in the treatment of myeloma patients with renal failure. ${ }^{46,47}$ We can hypothesize that in combination with plasma exchange, which removes the light chain, the kidney damage of myeloma is further alleviated. However, systematic studies and relevant guidelines in this area are 
lacking so far. Therefore, in the following studies, we can conduct relevant preclinical and clinical experiments to verify this conjecture.

\section{Hyperviscosity Syndrome}

Hyperviscosity syndrome (HVS) refers to the physiological changes and clinical sequelae associated with impaired blood flow caused by hyperviscosity of the plasma ${ }^{48}$ Since Waldenstrom first described macroglobulinemia, symptoms of high viscosity have been observed in patients. ${ }^{49,50}$ The most common monoclonal proteins that cause high viscosity are IgG, IgA, and IgM. IgM has a profound effect on blood cells and blood flow. Although serum viscosity initially increases linearly with increasing IgG levels it increases exponentially when the IgM concentration exceeds $3 \mathrm{~g} / \mathrm{dL}$, leading to symptoms associated with high viscosity. ${ }^{48,51,52}$ Waldenstrom macroglobulinemia (WM, also known as the lymphatic plasma cell lymphoma, LPL) is a monoclonal lymphatic proliferative disease that occurs in about $2 \%$ of non-Hodgkin's lymphoma cases and is characterized by the synthesis and secretion of large amounts of monoclonal IgM. ${ }^{53,54} \mathrm{WM}$ accounts for between $10 \%$ and $30 \%$ of cases of symptomatic high blood viscosity, while multiple myeloma accounts for between $2 \%$ and $6 \% .^{55}$

TPE can not only control symptomatic HVS in patients by the rapid reduction of paraprotein levels but can also be used for the prevention and long-term treatment of the condition. ${ }^{56}$ The immediate treatment of symptomatic HVS is aimed at reducing blood viscosity to control the symptoms while long-term treatment is aimed at controlling the underlying disease to prevent the production of monoclonal proteins. ${ }^{57}$ The treatment strategy for symptomatic HVS should be guided by a target serum viscosity. Since $70-80 \%$ of macromolecular proteins are present in blood vessels, a single exchange can remove up to $65 \%$ of these proteins in the body, typically $1-1.5$ plasma volumes per course of exchange, reducing viscosity by $20 \%-30 \%$, and two to three TPE sessions can reduce the serum IgM levels by $30 \%$ $60 \% .{ }^{52,56,58}$ In addition, the decrease in IgM was associated with a decrease in the incidence of infusion reactions, primarily allergic reactions, in rituximab therapy for lymphoplasmacytic lymphoma. ${ }^{59,60}$ Therefore, in the treatment of lymphatic plasmapheresis lymphoma, the combination of rituximab and plasmapheresis can be regarded as a new treatment method. Because TPE does not affect the underlying cause of the disease, chemotherapy is usually begun at the same time as TPE. Usually, it is only necessary to control the viscosity below the symptom threshold in patients, rather than to reduce it to normal. Keeping the serum viscosity below the threshold of symptoms in each patient can effectively prevent the recurrence of HVS. ${ }^{48,61}$

\section{Neurological Tumors}

\section{Thymoma-Related Myasthenia Gravis}

Thymoma is a rare malignant tumor of the thymus epithelium and is a common primary tumor of the mediastinum. Myasthenia gravis (MG) is the typical autoimmune manifestation of thymoma. ${ }^{62}$ About $35 \%$ of thymoma patients have myasthenia gravis. ${ }^{63} \mathrm{MG}$ is frequently caused by autoantibodies against the components of nicotinic acetylcholine receptor (AChR) on the postsynaptic membrane of the neuromuscular junction and is characterized by fatigue and muscle weakness. ${ }^{64-66}$ Apart from acetylcholine receptor autoantibodies (AChR-Ab), presynaptic membrane antibodies (PRSM-Ab) and anti-titin antibodies (Titin-Ab) may also be involved. ${ }^{67}$

TPE has become the standard treatment for MG. The indications for TPE include MG crisis, acute exacerbation of MG, and optimization of clinical status before thymectomy. ${ }^{68}$ Since TPE can relieve symptoms by reducing the titer of AChR-Abs in MG patients, plasma exchange has since been recommended for the treatment of thymoma-associated MG as well as for myasthenic crisis. ${ }^{69,70}$ TPE is also used as a preoperative preparation for thymoma resection, reducing the likelihood of myasthenic crisis and reducing the duration of mechanical ventilation (MV) and intensive care unit (ICU) hospitalization. $^{71,72}$

However, the available evidence indicates that TPE should only be used as a short-term therapy for MG since it can only improve the redistribution of AChR-Abs but cannot prevent their resynthesis. ${ }^{73} \mathrm{~T}$ lymphocytes (such as thymocytoma-derived CD4+T cells) and B lymphocytes as well as cytokines (such as IL-8 and IL-10) are involved in the occurrence and development of MG. ${ }^{21,30,74,75} \mathrm{In}$ addition to the elimination of pathological autoantibodies, TPE can also up-regulate immune tolerance and eliminate cytokines involved in MG development to achieve therapeutic 
effects. ${ }^{76}$ In addition, a study has shown that when DFPP is used to treat MG caused by thymoma, it can more effectively increase the expression of Treg cells, thereby benefiting MG patients through immunomodulatory effects. $^{21}$

Notably, in one case report, TPE not only reduced the size of the thymoma lesion in the patient but also restored the patient's muscle strength. ${ }^{77}$ Munakata and Nagane Y observed the efficacy of combined therapy with methyl-potent (HMP) MG (TPE+HMP) immediately after TPE. ${ }^{78,79}$ In the absence of sufficient large randomized controlled trials to evaluate the long-term outcomes of TPE in MG patients, due to the efficacy of this method has been proven, the feasibility of TPE for combination therapy in MG patients has become a new consideration.

\section{Paraneoplastic Neurological Syndrome}

Paraneoplastic neurological syndrome (PNS) is a malignancy-associated syndrome that has been shown to be immunemediated, yet affects any part of the nervous system, from nerves to muscles. ${ }^{80,81}$ About $50 \%$ of PNS patients possess anti-neurogenic autoantibodies that react with tumor antigens. ${ }^{82}$ The disease is caused by cross-reactions between the circulating antibodies and antigens expressed by the tumor cells. The most important relevant antibodies are anti-Hu (ANNA1) and anti-Yo (PCA1). ${ }^{83}$ PNS can be associated with any type of malignancy, and the most common tumor associated with PNS in adults is small cell lung cancer (SCLC). ${ }^{84}$

Since the effectiveness of TPE in reducing autoantibodies and immunoglobulin titers has been confirmed by many reports, TPE has been attempted as a treatment for PNS; the therapeutic effect of TPE on PNS, however, is mixed. There are individual cases showing the therapeutic effect of TPE on PNS and some researchers believe that TPE may mitigate the rapid development of PNS in patients without anti-neuronal antibodies, but most scholars believe that TPE cannot influence paraneoplastic symptoms. ${ }^{85-89}$ At present, the best treatment for PNS symptoms is to identify and eradicate potential malignant tumors. Nevertheless, patients with PNS symptoms should consider early active immunosuppression before malignant tumors are confirmed and TPE is often used to initiate immunosuppression. ${ }^{81,90}$ Interestingly, human chorionic gonadotropin (hCG) may be able to change the process of Hu-PNS, because hCG may have immunomodulatory activity. ${ }^{91}$

\section{Lambert-Eaton Muscle Weakness Syndrome}

Lambert-Eaton myasthenia syndrome (LEMS) is an autoimmune disease that occurs in the neuromuscular junction and belongs to the paraneoplastic syndromes. The disease is mainly caused by autoantibodies against the presynaptic anti-P/Q type voltage-gated calcium channel preventing the release of acetylcholine-containing vesicles, resulting in muscle weakness. ${ }^{92,93}$ Fifty to sixty percent of LEMS cases are tumor-related, the most important of which is small cell lung cancer (SCLC). ${ }^{94}$ When LEMS and SCLC coexist, the treatment of SCLC is the priority. ${ }^{95}$ The second is to choose 3,4-diaminopyridine (3,4-DAP) to strengthen neuromuscular transmission as a symptomatic treatment. ${ }^{96} \mathrm{TPE}$ and other immunomodulatory treatments mainly participate in the comprehensive treatment of LEMS after the failure of symptomatic treatment by reducing the autoantibody titer. ${ }^{97}$

However, TPE is not the standard treatment for LEMS. There are only a few studies that have demonstrated the efficacy of TPE in LEMS, ${ }^{98-100}$ and no prospective controlled evaluation has been published to date. Therefore, future work can be devoted to the evaluation of the efficacy of TPE on LEMS.

\section{Anti-N-Methyl-D-Aspartate Receptor (Anti-NMDAR) Encephalitis}

Anti-N-methyl-D-aspartate receptor (anti-NMDAR) encephalitis was first reported as a paraneoplastic syndrome. ${ }^{101,102}$ It is currently believed that the disease is an immune-mediated encephalitis and the cause of the disease is the development of autoantibodies against the synaptic NMDA receptor NR1 subunit on the cell surface. ${ }^{103-105}$ Ovarian teratomas have been shown to express NMDA receptors and, therefore, have a strong correlation with anti-NMDAR encephalitis. ${ }^{106}$ Thirty-five to sixty percent of anti-NMDAR encephalitis patients have potential tumors, $96 \%$ of which are ovarian or extra-ovarian teratomas and tumors. ${ }^{107,108}$

In addition to removing the tumor to eliminate the autoantibody production, TPE is usually the first-line treatment for anti-NMDAR encephalitis. Although some case reports have indicated that TPE treatment is ineffective for the disease, 
a large number of studies have proved its efficacy. In addition, based on the therapeutic efficacy of TPE, ASFA classifies TPE as a Class I indication. ${ }^{31}$

\section{Application of TPE in the Case of Cisplatin Overdose}

Cisplatin is the first heavy metal-based compound to have demonstrated anti-tumor activity. ${ }^{109}$ Its anti-cancer activity relies on the induction of apoptosis in cancer cells. The platinum-based compound is widely used in treating a variety of human cancers including cancers of the bladder, head and neck, lung, ovary, and testis. ${ }^{110}$ Ninety percent of the cisplatin that enters the body binds to circulating proteins, and most of this binding is irreversible. Although the reactivity of protein-bound cisplatin is lower than that of the unbound state, there is an exchangeable platinum pool that leads to additional toxicity. Occasionally, excessive cisplatin can cause toxic manifestations including vomiting, bone marrow suppression, and organ toxicity. ${ }^{111}$ Due to the dose-dependent nature of cisplatin, the severity of toxicity (including nephrotoxicity, gastrointestinal toxicity, neurotoxicity, ototoxicity, and myelotoxicity) of cisplatin is directly related to dose and time. ${ }^{112,113}$ Therefore, in the treatment of cisplatin in humans, the balance between anti-tumor efficacy and toxicity is always pursued to avoid more toxic and side effects. To alleviate the toxic side effects of cisplatin, scholars are conducting continuous research.

Due to its ability to clear plasma, TPE may be beneficial for the treatment of cisplatin excess. Clinical data have shown that TPE can significantly reduce the cisplatin serum concentration, reducing and eliminating the toxicity caused by excessive cisplatin. ${ }^{114}$

Guidelines and large randomized trials on the use of TPE for the treatment of cisplatin overdose are lacking, but there is already practical evidence that PE can be used for the treatment of cisplatin overdose, and we collected the cases published to date (Table 3). In seven cases, including a 13-year-old girl, although cisplatin overdose produced a series of toxic side-effects such as impaired renal function and hearing loss, most of the symptoms were reduced or even eliminated after TPE and other symptomatic treatments. In all cases, only one patient died. ${ }^{115}$ This patient was found to have renal insufficiency within 48 hours of the poisoning, and severe sepsis and apnea occurred on the eighth and eleventh days. During the autopsy, high concentrations of cisplatin were found in the patient's heart and peripheral blood. Regrettably, no studies related to DFPP and PA have been found in this regard.

Table 3 Report on TPE for Cisplatin Overdose

\begin{tabular}{|c|c|c|c|c|c|c|c|c|}
\hline Age & Sex & $\begin{array}{l}\text { Cancer } \\
\text { Types }\end{array}$ & Dosage & Treatment & IC & FC & Outcome & Reference \\
\hline 59 & M & $\begin{array}{l}\text { Esophageal } \\
\text { carcinoma }\end{array}$ & $300 \mathrm{ng} / \mathrm{m}^{2}$ & TPE+ GM-GSF & $2979 \mathrm{ng} / \mathrm{mL}$ & $185 \mathrm{ng} / \mathrm{mL}$ & $\begin{array}{l}\text { Renal function recovered and partial } \\
\text { remission of esophageal cancer was } \\
\text { achieved }\end{array}$ & {$[116]$} \\
\hline 68 & $\mathrm{~F}$ & $\begin{array}{l}\text { Ovarian } \\
\text { cancer }\end{array}$ & $280 \mathrm{ng} / \mathrm{m} 2$ & $\begin{array}{l}\text { TPE+HD+ GM-GSF+ } \\
\text { Prednisone }\end{array}$ & $2900 \mathrm{ng} / \mathrm{mL}$ & $200 \mathrm{ng} / \mathrm{mL}$ & $\begin{array}{l}\text { Hearing loss, no signs of recurrence of } \\
\text { ovarian cancer }\end{array}$ & {$[117]$} \\
\hline 48 & M & $\begin{array}{l}\text { Laryngeal } \\
\text { carcinoma }\end{array}$ & $400 \mathrm{ng} / \mathrm{m} 2$ & TPE+HD & $2470 \mathrm{ng} / \mathrm{mL}$ & $216 \mathrm{ng} / \mathrm{mL}$ & Full recovery without sequelae & {$[118]$} \\
\hline 63 & M & Lymphoma & Total $750 \mathrm{mg}$ & $\begin{array}{l}\text { TPE+HD+ } \\
\mathrm{N} \text {-acetylcytosine }\end{array}$ & - & - & Death & {$[115]$} \\
\hline 46 & $\mathrm{~F}$ & NSCLC & $225 \mathrm{ng} / \mathrm{m} 2$ & TPE+ Supportive care & - & - & Full recovery without sequelae & [119] \\
\hline 67 & M & $\begin{array}{l}\text { Esophageal } \\
\text { carcinoma }\end{array}$ & $240 \mathrm{ng} / \mathrm{m} 2$ & $\begin{array}{l}\text { TPE+ Intravenous } \\
\text { hydration+ Chemical } \\
\text { protectant }\end{array}$ & $2350 \mathrm{ng} / \mathrm{mL}$ & $110 \mathrm{ng} / \mathrm{mL}$ & $\begin{array}{l}\text { There were no significant complications } \\
\text { and only moderate hearing loss }\end{array}$ & [120] \\
\hline 13 & $\mathrm{~F}$ & Osteosarcoma & $240 \mathrm{ng} / \mathrm{m} 2$ & $\begin{array}{l}\text { TPE+Chemical } \\
\text { protectant }\end{array}$ & $8500 \mathrm{ng} / \mathrm{mL}$ & $110 \mathrm{ng} / \mathrm{mL}$ & $\begin{array}{l}\text { He regained impaired kidney function and } \\
\text { hearing }\end{array}$ & {$[121]$} \\
\hline
\end{tabular}

Abbreviations: IC, initial concentration, the initial plasma concentration of cisplatin; FC, final concentration, the final plasma concentration of cisplatin; M, male; F, female; HD, hemodialysis; GM-GSF, granulocyte macrophage colony stimulating factor; NSCLC, non-small cell lung cancer. 


\section{Adverse Events of TPE}

Although there is currently a lack of relevant trials and guidelines, the current evidence provides us with a new therapeutic idea: to increase the dose of cisplatin in the target area without increasing the concentration of cisplatin in the peripheral blood in the treatment of cancer patients with conventional dose of cisplatin combined with TPE, to enhance the therapeutic effect without increasing the side-effects.

The overall incidence of TPE clinical adverse events is relatively low and serious complications are rare, but the treatment is not completely risk-free and may even be fatal in severe cases. The severity of adverse events is divided into four levels (Table 4).

Although the incidence is low, TPE complications may appear at each step, including the primary disease, the choice and amount of anticoagulants, the type of replacement fluid, the choice of vascular access, and the choice of TPE method. ${ }^{122,123}$

Among all patients undergoing TPE, patients with anti-NMDA receptor encephalitis have the highest risk of complications. ${ }^{124}$

There are also differences in the incidence of adverse reactions caused by different anticoagulants. Commonly used anticoagulants include citrate and heparin. When using sodium citrate, attention should be paid to monitoring the citric acid concentration to prevent citrate poisoning. At the same time, because citrate combines with calcium ions resulting in anticoagulant properties, the use of citrate can also cause hypocalcemia. The main problems related to heparin are bleeding and protamine neutralization. ${ }^{125}$

Albumin solutions and FFP are commonly used during the TPE process to maintain plasma volume and prevent hypotension and edema. Adverse reactions are usually mild to moderate and serious complications are rare. Although FFP is more effective than albumin in replenishing normal body fluids and immune components, it also leads to a higher incidence of adverse reactions, often resulting in anaphylaxis. As albumin solutions are inactivated, the incidence of anaphylaxis is lower than FFP but the risk of hypotension and metabolic alkalosis is higher. ${ }^{124,126-128}$

Peripheral venipuncture sites may cause peripheral soft tissue damage, bleeding, infection, catheter blockage, thrombosis, and even embolism. Related complications such as bleeding or hematoma caused by central venous access are also inevitable. In addition, the patient's anxiety during puncture may even induce a vasovagal response. ${ }^{123,129,130}$

Different TPE choices have different chances of causing adverse reactions. Centrifugation and filtration are the two main technologies used for plasma separation. Filtration results in almost twice the incidence of adverse reactions than centrifugation. ${ }^{123,131}$ In addition, since there are fewer separators that can separate albumin, which has a similar molecular weight to the immunoglobulins present in autoimmune disorders, insufficient albumin supplementation during DFPP can easily lead to a loss of albumin and a decrease in blood volume. ${ }^{132}$ Because DFPP can selectively remove

Table 4 Severity of Adverse Events

\begin{tabular}{|l|l|l|l|}
\hline Grade & Severity & Treatment Requires & Classical Symptom \\
\hline Grade I & Mild & No intervention required & Week of mouth sting \\
\hline Grade II & Moderate & Need intervention but can complete treatment & $\begin{array}{l}\text { Paresthesia, } \\
\text { Mild hypotension, } \\
\text { Nausea, } \\
\text { Urticaria }\end{array}$ \\
\hline Grade III & Severe & Procedure interrupted or abandoned & $\begin{array}{l}\text { Prolonged vagal response time, } \\
\text { Decreased level of consciousness, } \\
\text { Muscle contractions, } \\
\text { Hand and foot convulsions, } \\
\text { Seizures, } \\
\text { Arrhythmia }\end{array}$ \\
\hline Grade IV & Fatal & Lethality & No response to treatment \\
\hline
\end{tabular}


macromolecular immunoglobulins, high molecular weight coagulation factors cannot be spared. According to reports, DFPP can significantly reduce the concentration of FXIII and fibrinogen, leading to the risk of bleeding. ${ }^{133,134}$ In comparison, the adverse reaction rate of PA is significantly lower than that of PE and DFPP. Adsorbents are needed in the PA process, including both biosorbents and non-biosorbents. Although the affinity of biosorbents is higher than that of non-biosorbents, they are difficult to sterilize, resulting in a higher risk of infection. ${ }^{23}$ Although their incidence is relatively minor, complications such as hypotension, headache, and nausea, as well as fibrinogen depletion, anticoagulation, and catheter-related bleeding are inevitable, ${ }^{123}$ of which the most common complications are hypotension and fibrinogen depletion. ${ }^{135}$ However, antithrombin and most other coagulation factors are not easily reduced. ${ }^{136}$

Due to the large amount of fluid in and out, serious cardiovascular events such as dehydration, congestive heart failure, pulmonary edema, and pulmonary embolism, as well as serious complications such as cerebrovascular accidents and deaths, are extremely low, but they cannot be ignored. Therefore, an unstable hemodynamic state and severe infection are listed as a contraindication for TPE. ${ }^{137}$

Although the most common TPE complications are mild, the risk of severe complications should be taken seriously. For the potential complications that may occur during the TPE process, symptomatic measures can be taken to prevent their occurrence and reduce their incidence. If conditions permit, a more appropriate TPE method or PA with fewer complications can be selected. In addition, medical staff should be vigilant in identifying the symptoms of complications during the TPE process to prevent the development of serious or even life-threatening conditions.

\section{Conclusions}

TPE is a relatively safe blood purification method, which is widely used for treating various systemic diseases. Nowadays, although some cancers can be cured, there are others that do not respond to traditional treatment methods, and the temporary treatment of cancer is relatively limited. The development of new treatment methods has, therefore, become a top priority. TPE treatment, because of its ability to remove pathological components, has become an important treatment option for complications related to malignant tumors. However, there is currently a lack of sufficiently strong evidence to prove that TPE can reduce the tumor burden and improve the survival of patients with malignant tumors. Therefore, TPE tends to be used more for the control of symptoms caused by malignant tumors and the prevention of certain symptoms, such as reversing renal failure in patients with multiple myeloma by removing circulating light chains, controlling and preventing symptoms in patients with HVS, and removing autoantibodies to reduce and prevent complications and paraneoplastic syndromes in patients with nervous system tumors. It is important that the role of traditional treatment methods is not ignored when TPE is used for treatment. It is worth noting that the immune effects of TPE include regulating immune cell activity, clearing immune factors, and reducing autoantibody titers and immunoglobulin concentrations.

This review lists the advantages and disadvantages of the various TPE methods. Medical staff can avoid unnecessary side-effects and maximize the therapeutic effect of TPE by considering the specific characteristics of the TPE method used. Only a few of the diseases applicable to TPE treatment mentioned in this review are included in the ASFA guidelines, with the rest not having been approved by ASFA due to a lack of evidential support. Therefore, in future work, we need more prospective randomized controlled trials to define application of TPE in various diseases. In addition, this review introduces the application of TPE to a typical chemotherapeutic drug, cisplatin, overdose. Many reports have shown that TPE has a significant effect in eliminating the toxic side-effects caused by cisplatin overdose without producing new sequelae, thus TPE may become a way of reducing these side-effects besides chemical antidotes. Although TPE is relatively safe, various complications are inevitable. With careful operation and timely treatment of minor complications, we should be alert to the presence of serious complications and the evolution of mild to moderate complications and develop appropriate treatment plans. Careful inspection and monitoring is thus an effective prerequisite for the successful execution of TPE.

With the diversity of cancer treatments, new therapeutic approaches are imminent. Since the advent of TPE, this modality has been used in the treatment of many diseases. With the development of medicine, TPE is still the first-line treatment for some diseases, although other better treatment strategies are already available for some indications of TPE. In this paper, we introduce the use of TPE in tumor treatment, summarize its therapeutic effects, and speculate that TPE can be used individually to replace or in combination to assist existing methods of tumor treatment, thus demonstrating 
the safety and clinical efficacy of TPE in the treatment of tumors and their complications. This may play a guiding role for the use of TPE in malignancy.

In our conclusion, TPE is not a separate treatment, it is part of a patient-centered comprehensive treatment. In addition, due to the limited number of analyzed articles, different research methods, and possible publication deviations, the above conclusions should be interpreted more cautiously.

\section{Abbreviations}

TPE, Therapeutic plasma exchange; PE, plasma exchange; DFPP, double-filtered plasmapheresis; PA, plasma adsorption; SFPP, single-filter plasmapheresis; FFP, fresh frozen plasma; GBS, Guillain-Barre syndrome; CIDP, chronic inflammatory demyelinating neuropathy; MS, multiple sclerosis; NMO, neuromyelitis optica; IL-18, interleukin - 18; IL-17, interleukin - 17; MM, Multiple myeloma; FLCs, free light chains; HVS, free light chains; WM, Waldenstrom macroglobulinemia; LPL, lymphatic plasma cell lymphoma; MG, myasthenia gravis; AChR, acetylcholine receptor; AChR-Ab, acetylcholine receptor autoantibodies; PRSM-Ab, presynaptic membrane antibodies; Titin-Ab, anti-titin antibodies; MV, mechanical ventilation; ICU, intensive care unit; PNS, paraneoplastic neurological syndrome; SCLC, small cell lung cancer; hCG, human chorionic gonadotropin; LEMS, Lambert-Eaton myasthenia syndrome; 3,4-DAP, 3,4-diaminopyridine; anti-NMDAR, Anti-N-methyl-D-aspartate receptor.

\section{Disclosure}

The authors declare that they have no conflicts of interest in this work.

\section{References}

1. Kuang W, Tan J, Yuan X, et al. Plasma exchange therapy holds promise in the management of advanced cancer. Med Hypotheses. 2009;72 (5):533-534. doi:10.1016/j.mehy.2008.11.030

2. Tsimberidou AM, Fountzilas E, Nikanjam M, Kurzrock R. Review of precision cancer medicine: evolution of the treatment paradigm. Cancer Treat Rev. 2020;86:102019. doi:10.1016/j.ctrv.2020.102019

3. Clark WF, Huang SS. Introduction to therapeutic plasma exchange. Transfus Apher Sci. 2019;58(3):228-229. doi:10.1016/j.transci.2019.04.004

4. Tiwari AK, Bhardwaj G, Aggarwal G, et al. Changing trends in therapeutic plasmapheresis: an Indian perspective. Ther Apher Dial. 2017;21 (5):500-506. doi:10.1111/1744-9987.12549

5. Brunskill SJ, Tusold A, Benjamin S, Stanworth SJ, Murphy MF. A systematic review of randomized controlled trials for plasma exchange in the treatment of thrombotic thrombocytopenic purpura. Transfus Med. 2007;17(1):17-35. doi:10.1111/j.1365-3148.2006.00720.x

6. Scully M, Hunt BJ, Benjamin S, et al. Guidelines on the diagnosis and management of thrombotic thrombocytopenic purpura and other thrombotic microangiopathies. Br J Haematol. 2012;158(3):323-335. doi:10.1111/j.1365-2141.2012.09167.x

7. Ahmadpoor P, Aglae C, Cariou S, et al. Physiological role of plasma and its components and the clinical implications of different methods of apheresis: a narrative review. Ther Apher Dial. 2021;25(3):262-272. doi:10.1111/1744-9987.13567

8. Connelly-Smith LS, Linenberger ML. Therapeutic apheresis for patients with cancer. Cancer Control. 2015;22(1):60-78. doi:10.1177/ 107327481502200109

9. Dumas G, Merceron S, Zafrani L, et al. [Hyperviscosity syndrome]. Rev Med Interne. 2015;36(9):588-595. French. doi:10.1016/j. revmed.2015.02.005

10. Perez Rogers A, Estes M. Hyperviscosity Syndrome. In: StatPearls. Treasure Island (FL): StatPearls Publishing Copyright (C 2021, StatPearls Publishing LLC.; 2021.

11. Higdon ML, Atkinson CJ, Lawrence KV. Oncologic emergencies: recognition and initial management. Am Fam Physician. 2018;97 (11):741-748.

12. Nakanishi T, Suzuki N, Kuragano T, Nagasawa Y, Hasuike Y. Current topics in therapeutic plasmapheresis. Clin Exp Nephrol. 2014;18 (1):41-49. doi:10.1007/s10157-013-0838-0

13. Hirano R, Namazuda K, Suemitsu J, Harashima T, Hirata N. Plasma separation using a membrane. Transfus Apher Sci. 2017;56(5):649-653. doi:10.1016/j.transci.2017.08.008

14. Mineshima M. Double filtration plasmapheresis: determination of the optimal albumin concentration in the supplementation fluid. Transfus Apher Sci. 2017;56(5):654-656. doi:10.1016/j.transci.2017.08.009

15. Ogawa T, Yoshino H, Sasaki Y, et al. Our approaches to selective plasma exchange. Contrib Nephrol. 2018;196:194-199.

16. Zanatta E, Cozzi M, Marson P, Cozzi F. The role of plasma exchange in the management of autoimmune disorders. Br J Haematol. $2019 ; 186$ (2):207-219. doi:10.1111/bjh.15903

17. McLeod BC. Therapeutic apheresis: use of human serum albumin, fresh frozen plasma and cryosupernatant plasma in therapeutic plasma exchange. Best Pract Res Clin Haematol. 2006;19(1):157-167. doi:10.1016/j.beha.2005.01.004

18. Yeh JH, Chiu HC. Comparison between double-filtration plasmapheresis and immunoadsorption plasmapheresis in the treatment of patients with myasthenia gravis. $J$ Neurol. 2000;247(7):510-513. doi:10.1007/s004150070149

19. Chauvel F, Reboul P, Cariou S, et al. Use of double filtration plasmapheresis for the treatment of acquired thrombocytopenic thrombotic purpura. Ther Apher Dial. 2020;24(6):709-717. doi:10.1111/1744-9987.13477 
20. Higashihara T, Kawase M, Kobayashi M, et al. Evaluating the efficacy of double-filtration plasmapheresis in treating five patients with drug-resistant pemphigus. Ther Apher Dial. 2017;21(3):243-247. doi:10.1111/1744-9987.12557

21. Zhang L, Liu J, Wang H, et al. Double filtration plasmapheresis benefits myasthenia gravis patients through an immunomodulatory action. J Clin Neurosci. 2014;21(9):1570-1574. doi:10.1016/j.jocn.2013.11.046

22. Onohara T, Sakamoto Y, Inoue S. Plasma adsorption membranes are able to efficiently remove high mobility group box-1 (HMGB-1). $J$ Nippon Med Sch. 2018;85(3):150-156. doi:10.1272/jnms.JNMS.2018_85-22

23. Hirata N, Kuriyama T, Yamawaki N. Immusorba TR and PH. Ther Apher Dial. 2003;7(1):85-90. doi:10.1046/j.1526-0968.2003.00010.x

24. Hirano R, Hirata N. Immunoadsorption using Immusorba TR and PH. Transfus Apher Sci. 2017;56(5):661-665. doi:10.1016/j. transci.2017.08.011

25. Hughes RA, Swan AV, van Doorn PA. Intravenous immunoglobulin for Guillain-Barré syndrome. Cochrane Database Syst Rev. 2014;2014(9): Cd002063.

26. Galldiks N, Burghaus L, Dohmen C, et al. Immunoadsorption in patients with chronic inflammatory demyelinating polyradiculoneuropathy with unsatisfactory response to first-line treatment. Eur Neurol. 2011;66(4):183-189. doi:10.1159/000331011

27. Schimrigk S, Faiss J, Köhler W, et al. Escalation therapy of steroid refractory multiple sclerosis relapse with tryptophan immunoadsorption observational multicenter study with 147 patients. Eur Neurol. 2016;75(5-6):300-306. doi:10.1159/000447059

28. Kobayashi M, Nanri K, Taguchi T, et al. Immunoadsorption therapy for neuromyelitis optica spectrum disorders long after the acute phase. $J$ Clin Apher. 2015;30(1):43-45. doi:10.1002/jca.21324

29. Loo CY, Mohamed Said MS, Mohd R, et al. Immunoadsorption and plasmapheresis are equally efficacious as adjunctive therapies for severe lupus nephritis. Transfus Apher Sci. 2010;43(3):335-340. doi:10.1016/j.transci.2010.10.003

30. Baggi F, Ubiali F, Nava S, et al. Effect of IgG immunoadsorption on serum cytokines in MG and LEMS patients. J Neuroimmunol. 2008;201202:104-110. doi:10.1016/j.jneuroim.2008.05.026

31. Padmanabhan A, Connelly-Smith L, Aqui N, et al. Guidelines on the use of therapeutic apheresis in clinical practice - evidence-based approach from the writing committee of the American Society for Apheresis: the eighth special issue. J Clin Apher. 2019;34(3):171-354. doi:10.1002/ jca. 21705

32. Knudsen LM, Hjorth M, Hippe E. Renal failure in multiple myeloma: reversibility and impact on the prognosis. Nordic Myeloma Study Group. Eur J Haematol. 2000;65(3):175-181. doi:10.1034/j.1600-0609.2000.90221.x

33. Dimopoulos MA, Kastritis E, Rosinol L, Bladé J, Ludwig H. Pathogenesis and treatment of renal failure in multiple myeloma. Leukemia. 2008;22(8):1485-1493. doi:10.1038/leu.2008.131

34. Bladé J, Rosiñol L. Renal, hematologic and infectious complications in multiple myeloma. Best Pract Res Clin Haematol. 2005;18(4):635-652. doi:10.1016/j.beha.2005.01.013

35. Defronzo RA, Humphrey RL, Wright JR, Cooke CR. Acute renal failure in multiple myeloma. Medicine (Baltimore). 1975;54(3):209-223. doi:10.1097/00005792-197505000-00003

36. Feest TG, Burge PS, Cohen SL. Successful treatment of myeloma kidney by diuresis and plasmaphoresis. Br Med J. 1976;1(6008):503-504. doi:10.1136/bmj.1.6008.503

37. Johnson WJ, Kyle RA, Pineda AA, O’Brien PC, Holley KE. Treatment of renal failure associated with multiple myeloma. Plasmapheresis, hemodialysis, and chemotherapy. Arch Intern Med. 1990;150(4):863-869. doi:10.1001/archinte.1990.00390160111022

38. Zucchelli P, Pasquali S, Cagnoli L, Ferrari G. Controlled plasma exchange trial in acute renal failure due to multiple myeloma. Kidney Int. 1988;33(6):1175-1180. doi:10.1038/ki.1988.127

39. Clark WF, Stewart AK, Rock GA, et al. Plasma exchange when myeloma presents as acute renal failure: a randomized, controlled trial. Ann Intern Med. 2005;143(11):777-784. doi:10.7326/0003-4819-143-11-200512060-00005

40. Leung N, Gertz MA, Zeldenrust SR, et al. Improvement of cast nephropathy with plasma exchange depends on the diagnosis and on reduction of serum free light chains. Kidney Int. 2008;73(11):1282-1288. doi:10.1038/ki.2008.108

41. Yu X, Gan L, Wang Z, Dong B, Chen X. Chemotherapy with or without plasmapheresis in acute renal failure due to multiple myeloma: a meta-analysis. Int J Clin Pharmacol Ther. 2015;53(5):391-397. doi:10.5414/CP202245

42. Madore F. Does plasmapheresis have a role in the management of myeloma cast nephropathy? Nat Clin Pract Nephrol. 2006;2(8):406-407. doi:10.1038/ncpneph0229

43. Leung N. Plasma exchange in multiple myeloma. Ann Intern Med. 2006;144(6):455; author reply 455. doi:10.7326/0003-4819-1446-200603210-00021

44. Chapdelaine I, Madore F. Plasmapheresis in myeloma cast nephropathy. Clin Nephrol. 2013;79(1):72-77. doi:10.5414/CN107064

45. Premuzic V, Batinic J, Roncevic P, Basic-Jukic N, Nemet D, Jelakovic B. Role of plasmapheresis in the management of acute kidney injury in patients with multiple myeloma: should we abandon it? Ther Apher Dial. 2018;22(1):79-86. doi:10.1111/1744-9987.12606

46. Grzasko N, Morawska M, Hus M. Optimizing the treatment of patients with multiple myeloma and renal impairment. Clin Lymphoma Myeloma Leuk. 2015;15(4):187-198. doi:10.1016/j.clml.2014.09.012

47. Fabbrini P, Finkel K, Gallieni M, et al. Light chains removal by extracorporeal techniques in acute kidney injury due to multiple myeloma: a position statement of the Onconephrology Work Group of the Italian Society of Nephrology. J Nephrol. 2016;29(6):735-746. doi:10.1007/ s40620-016-0347-9

48. Stone MJ. Waldenström's macroglobulinemia: hyperviscosity syndrome and cryoglobulinemia. Clin Lymphoma Myeloma. 2009;9(1):97-99. doi:10.3816/CLM.2009.n.026

49. Ballestri M, Ferrari F, Magistroni R, et al. Plasma exchange in acute and chronic hyperviscosity syndrome: a rheological approach and guidelines study. Ann Ist Super Sanita. 2007;43(2):171-175.

50. Anderson KC, Alsina M, Bensinger W, et al. Waldenström's macroglobulinemia/lymphoplasmacytic lymphoma, version 2.2013. J Natl Compr Canc Netw. 2012;10(10):1211-1219. doi:10.6004/jnccn.2012.0128

51. Fahey JL, Barth WF, Solomon A. Serum hyperviscosity syndrome. JAMA. 1965;192:464-467. doi:10.1001/jama.1965.03080190030008

52. Kwaan HC. Hyperviscosity in plasma cell dyscrasias. Clin Hemorheol Microcirc. 2013;55(1):75-83. doi:10.3233/CH-131691

53. Merlini G, Baldini L, Broglia C, et al. Prognostic factors in symptomatic Waldenstrom's macroglobulinemia. Semin Oncol. 2003;30 (2):211-215. doi:10.1053/sonc.2003.50064 
54. Wang H, Chen Y, Li F, et al. Temporal and geographic variations of Waldenstrom macroglobulinemia incidence: a large population-based study. Cancer. 2012;118(15):3793-3800. doi:10.1002/cncr.26627

55. French AI. [Management of splenectomized or sickle cell anemia patients in city medicine]. Presse Med. 2003;32(28 Suppl):S31-34. French.

56. Treon SP. How I treat Waldenström macroglobulinemia. Blood. 2009;114(12):2375-2385. doi:10.1182/blood-2009-05-174359

57. Stone MJ, Bogen SA. Evidence-based focused review of management of hyperviscosity syndrome. Blood. 2012;119(10):2205-2208. doi:10.1182/blood-2011-04-347690

58. Stone MJ, Bogen SA. Role of plasmapheresis in Waldenström's macroglobulinemia. Clin Lymphoma Myeloma Leuk. 2013;13(2):238-240. doi:10.1016/j.clml.2013.02.013

59. Tsujita Y, Imai K, Honma K, Kamae C, Horiuchi T, Nonoyama S. A severe anaphylactic reaction associated with IgM-class anti-human IgG antibodies in a hyper-IgM syndrome type 2 patient. J Clin Immunol. 2018;38(1):144-148. doi:10.1007/s10875-017-0466-7

60. Salles G, Barrett M, Foà R, et al. Rituximab in B-cell hematologic malignancies: a review of 20 years of clinical experience. Adv Ther. 2017;34 (10):2232-2273. doi:10.1007/s12325-017-0612-x

61. Stone MJ, Pascual V. Pathophysiology of Waldenström's macroglobulinemia. Haematologica. 2010;95(3):359-364. doi:10.3324/ haematol.2009.017251

62. Müllges W, Stoll G. [Myasthenia gravis]. Nervenarzt. 2019;90(10):1055-1066. German. doi:10.1007/s00115-019-00798-8

63. Zieliński M. Management of myasthenic patients with thymoma. Thorac Surg Clin. 2011;21(1):47-57, vi. doi:10.1016/j.thorsurg.2010.08.009

64. Jani-Acsadi A, Lisak RP. Myasthenia gravis. Curr Treat Options Neurol. 2010;12(3):231-243. doi:10.1007/s11940-010-0070-0

65. Querol L, Illa I. Myasthenia gravis and the neuromuscular junction. Curr Opin Neurol. 2013;26(5):459-465. doi:10.1097/ WCO.0b013e328364c079

66. Gilhus NE, Verschuuren JJ. Myasthenia gravis: subgroup classification and therapeutic strategies. Lancet Neurol. 2015;14(10):1023-1036. doi:10.1016/S1474-4422(15)00145-3

67. Nguyen-Cao TM, Gelinas D, Griffin R, Mondou E. Myasthenia gravis: historical achievements and the "golden age" of clinical trials. J Neurol Sci. 2019;406:116428. doi:10.1016/j.jns.2019.116428

68. Mandawat A, Mandawat A, Kaminski HJ, Shaker ZA, Alawi AA, Alshekhlee A. Outcome of plasmapheresis in myasthenia gravis: delayed therapy is not favorable. Muscle Nerve. 2011;43(4):578-584. doi:10.1002/mus.21924

69. Trikha I, Singh S, Goyal V, Shukla G, Bhasin R, Behari M. Comparative efficacy of low dose, daily versus alternate day plasma exchange in severe myasthenia gravis: a randomised trial. J Neurol. 2007;254(8):989-995. doi:10.1007/s00415-006-0235-7

70. Tormoehlen LM, Pascuzzi RM. Thymoma, myasthenia gravis, and other paraneoplastic syndromes. Hematol Oncol Clin North Am. 2008;22 (3):509-526. doi:10.1016/j.hoc.2008.03.004

71. Blichfeldt-Lauridsen L, Hansen BD. Anesthesia and myasthenia gravis. Acta Anaesthesiol Scand. 2012;56(1):17-22. doi:10.1111/j.13996576.2011.02558.x

72. Reis TA, Cataneo DC, Cataneo AJM. Clinical usefulness of prethymectomy plasmapheresis in patients with myasthenia gravis: a systematic review and meta-analysis. Interact Cardiovasc Thorac Surg. 2019;29(6):867-875. doi:10.1093/icvts/ivz186

73. Köhler W, Bucka C, Klingel R. A randomized and controlled study comparing immunoadsorption and plasma exchange in myasthenic crisis J Clin Apher. 2011;26(6):347-355. doi:10.1002/jca.20317

74. Ströbel P, Preisshofen T, Helmreich M, Müller-Hermelink HK, Marx A. Pathomechanisms of paraneoplastic myasthenia gravis. Clin Dev Immunol. 2003;10(1):7-12. doi:10.1080/10446670310001598528

75. Yeh JH, Wang SH, Chien PJ, Shih CM, Chiu HC. Changes in serum cytokine levels during plasmapheresis in patients with myasthenia gravis Eur J Neurol. 2009;16(12):1318-1322. doi:10.1111/j.1468-1331.2009.02729.x

76. Liu JF, Wang WX, Xue J, et al. Comparing the autoantibody levels and clinical efficacy of double filtration plasmapheresis, immunoadsorption, and intravenous immunoglobulin for the treatment of late-onset myasthenia gravis. Ther Apher Dial. 2010;14(2):153-160. doi:10.1111/j.17449987.2009.00751.x

77. Jiang W, Yu Q. Case report of thymoma tumor reduction following plasmapheresis. Medicine (Baltimore). 2015;94(47):e2173. doi:10.1097/ MD.0000000000002173

78. Munakata R, Utsugisawa K, Nagane Y, et al. The effect of combined therapy with immunoadsorption and high-dose intravenous methylprednisolone on myasthenia gravis. Eur Neurol. 2002;48(2):115-117. doi:10.1159/000062987

79. Nagane Y, Utsugisawa K, Obara D, Kondoh R, Terayama Y. Efficacy of low-dose FK506 in the treatment of Myasthenia gravis-a randomized pilot study. Eur Neurol. 2005;53(3):146-150. doi:10.1159/000085833

80. Darnell RB, Posner JB. Paraneoplastic syndromes involving the nervous system. N Engl J Med. 2003;349(16):1543-1554. doi:10.1056/ NEJMra023009

81. Vernino S, O’Neill BP, Marks RS, O’Fallon JR, Kimmel DW. Immunomodulatory treatment trial for paraneoplastic neurological disorders Neuro Oncol. 2004;6(1):55-62. doi:10.1215/S1152851703000395

82. Blaes F. Paraneoplastic neurological syndromes-diagnosis and management. Curr Pharm Des. 2012;18(29):4518-4525. doi:10.2174/ 138161212802502323

83. Sculier C, Bentea G, Ruelle L, et al. Autoimmune paraneoplastic syndromes associated to lung cancer: a systematic review of the literature: part 5: neurological auto-antibodies, discussion, flow chart, conclusions. Lung Cancer. 2017;111:164-175. doi:10.1016/j.lungcan.2017.07.026

84. Höftberger R, Rosenfeld MR, Dalmau J. Update on neurological paraneoplastic syndromes. Curr Opin Oncol. 2015;27(6):489-495. doi:10.1097/CCO.0000000000000222

85. Greenlee JE. Treatment of paraneoplastic cerebellar degeneration. Curr Treat Options Neurol. 2013;15(2):185-200. doi:10.1007/s11940-0120215-4

86. Blaes F. Immunotherapeutic approaches to paraneoplastic neurological disorders. Expert Opin Biol Ther. 2002;2(4):419-430. doi:10.1517/ 14712598.2.4.419

87. Bradley WH, Dottino PR, Rahaman J. Paraneoplastic cerebellar degeneration in ovarian carcinoma: case report with review of immune modulation. Int J Gynecol Cancer. 2008;18(6):1364-1367. doi:10.1111/j.1525-1438.2007.01173.x

88. Antoine JC, Mosnier JF, Absi L, Convers P, Honnorat J, Michel D. Carcinoma associated paraneoplastic peripheral neuropathies in patients with and without anti-onconeural antibodies. J Neurol Neurosurg Psychiatry. 1999;67(1):7-14. doi:10.1136/jnnp.67.1.7 
89. Tschernatsch M, Stolz E, Strittmatter M, Kaps M, Blaes F. Antinuclear antibodies define a subgroup of paraneoplastic neuropathies: clinical and immunological data. J Neurol Neurosurg Psychiatry. 2005;76(12):1702-1706. doi:10.1136/jnnp.2003.033225

90. Leypoldt F, Wandinger KP. Paraneoplastic neurological syndromes. Clin Exp Immunol. 2014;175(3):336-348. doi:10.1111/cei.12185

91. van Broekhoven F, de Graaf MT, Bromberg JE, et al. Human chorionic gonadotropin treatment of anti-Hu-associated paraneoplastic neurological syndromes. J Neurol Neurosurg Psychiatry. 2010;81(12):1341-1344. doi:10.1136/jnnp.2009.177865

92. Keogh M, Sedehizadeh S, Maddison P. Treatment for Lambert-Eaton myasthenic syndrome. Cochrane Database Syst Rev. 2011;2011(2): Cd003279.

93. Titulaer MJ, Lang B, Verschuuren JJ. Lambert-Eaton myasthenic syndrome: from clinical characteristics to therapeutic strategies. Lancet Neurol. 2011;10(12):1098-1107. doi:10.1016/S1474-4422(11)70245-9

94. Lipka AF, Boldingh MI, van Zwet EW, et al. Long-term follow-up, quality of life, and survival of patients with Lambert-Eaton myasthenic syndrome. Neurology. 2020;94(5):e511-e520. doi:10.1212/WNL.0000000000008747

95. Tarr TB, Wipf P, Meriney SD. Synaptic pathophysiology and treatment of Lambert-Eaton myasthenic syndrome. Mol Neurobiol. 2015;52 (1):456-463. doi:10.1007/s12035-014-8887-2

96. Bekircan-Kurt CE, Derle Çiftçi E, Kurne AT, Anlar B. Voltage gated calcium channel antibody-related neurological diseases. World J Clin Cases. 2015;3(3):293-300. doi:10.12998/wjcc.v3.i3.293

97. Mantegazza R, Meisel A, Sieb JP, Le Masson G, Desnuelle C, Essing M. The European LEMS Registry: baseline demographics and treatment approaches. Neurol Ther. 2015;4(2):105-124. doi:10.1007/s40120-015-0034-0

98. Lehmann HC, Hartung HP, Hetzel GR, Stüve O, Kieseier BC. Plasma exchange in neuroimmunological disorders: part 2. Treatment of neuromuscular disorders. Arch Neurol. 2006;63(8):1066-1071. doi:10.1001/archneur.63.8.1066

99. Newsom-Davis J, Murray NM. Plasma exchange and immunosuppressive drug treatment in the Lambert-Eaton myasthenic syndrome. Neurology. 1984;34(4):480-485. doi:10.1212/WNL.34.4.480

100. Lang B, Newsom-Davis J, Wray D, Vincent A, Murray N. Autoimmune aetiology for myasthenic (Eaton-Lambert) syndrome. Lancet. 1981;2 (8240):224-226. doi:10.1016/S0140-6736(81)90474-8

101. Vitaliani R, Mason W, Ances B, Zwerdling T, Jiang Z, Dalmau J. Paraneoplastic encephalitis, psychiatric symptoms, and hypoventilation in ovarian teratoma. Ann Neurol. 2005;58(4):594-604. doi:10.1002/ana.20614

102. Mathis S, Pin JC, Pierre F, et al. Anti-NMDA receptor encephalitis during pregnancy: a case report. Medicine (Baltimore). $2015 ; 94(26)$ :e1034. doi:10.1097/MD.0000000000001034

103. Mann AP, Grebenciucova E, Lukas RV. Anti-N-methyl-D-aspartate-receptor encephalitis: diagnosis, optimal management, and challenges. Ther Clin Risk Manag. 2014;10:517-525. doi:10.2147/TCRM.S61967

104. DeSena AD, Noland DK, Matevosyan K, et al. Intravenous methylprednisolone versus therapeutic plasma exchange for treatment of anti-N-methyl-D-aspartate receptor antibody encephalitis: a retrospective review. J Clin Apher. 2015;30(4):212-216. doi:10.1002/jca.21363

105. Chourasia N, Watkins MW, Lankford JE, Kass JS, Kamdar A. An infant born to a mother with anti-N-methyl-d-aspartate receptor encephalitis. Pediatr Neurol. 2018;79:65-68. doi:10.1016/j.pediatrneurol.2017.11.010

106. Titulaer MJ, McCracken L, Gabilondo I, et al. Late-onset anti-NMDA receptor encephalitis. Neurology. 2013;81(12):1058-1063. doi:10.1212/ WNL.0b013e3182a4a49c

107. Lamale-Smith LM, Moore GS, Guntupalli SR, Scott JB. Maternal-fetal transfer of anti-N-methyl-D-aspartate receptor antibodies. Obstet Gynecol. 2015;125(5):1056-1058. doi:10.1097/AOG.0000000000000548

108. Altintas A, Dargvainiene J, Schneider-Gold C, et al. Gender issues of antibody-mediated diseases in neurology: (NMOSD/autoimmune encephalitis/MG). Ther Adv Neurol Disord. 2020;13:1756286420949808. doi:10.1177/1756286420949808

109. Galluzzi L, Senovilla L, Vitale I, et al. Molecular mechanisms of cisplatin resistance. Oncogene. 2012;31(15):1869-1883. doi:10.1038/ onc. 2011.384

110. Dasari S, Tchounwou PB. Cisplatin in cancer therapy: molecular mechanisms of action. Eur J Pharmacol. 2014;740:364-378. doi:10.1016/j. ejphar.2014.07.025

111. Qi L, Luo Q, Zhang Y, Jia F, Zhao Y, Wang F. Advances in toxicological research of the anticancer drug cisplatin. Chem Res Toxicol. 2019;32 (8):1469-1486. doi:10.1021/acs.chemrestox.9b00204

112. Perše M. Cisplatin mouse models: treatment, toxicity and translatability. Biomedicines. 2021;9(10):1406. doi:10.3390/biomedicines9101406

113. Murata S, Onozawa S, Oda T, et al. Pharmacologic advantages of negative-balance isolated pelvic perfusion: achievement of intensive exposure of the pelvis to platinum without systemic leakage. Radiology. 2012;262(2):503-510. doi:10.1148/radiol.11102453

114. Reeves HM, Winters JL. The mechanisms of action of plasma exchange. Br J Haematol. 2014;164(3):342-351. doi:10.1111/bjh.12629

115. Charlier C, Kintz P, Dubois N, Plomteux G. Fatal overdosage with cisplatin. J Anal Toxicol. 2004;28(2):138-140. doi:10.1093/jat/28.2.138

116. Jung HK, Lee J, Lee SN. A case of massive cisplatin overdose managed by plasmapheresis. Korean J Intern Med. 1995;10(2):150-154. doi:10.3904/kjim.1995.10.2.150

117. Chu G, Mantin R, Shen YM, Baskett G, Sussman H. Massive cisplatin overdose by accidental substitution for carboplatin. Toxicity and management. Cancer. 1993;72(12):3707-3714. doi:10.1002/1097-0142(19931215)72:12<3707::AID-CNCR2820721224>3.0.CO;2-U

118. Choi JH, Oh JC, Kim KH, Chong SY, Kang MS, Oh DY. Successful treatment of cisplatin overdose with plasma exchange. Yonsei Med J. 2002;43(1):128-132. doi:10.3349/ymj.2002.43.1.128

119. Hofmann G, Bauernhofer T, Krippl P, et al. Plasmapheresis reverses all side-effects of a cisplatin overdose-a case report and treatment recommendation. BMC Cancer. 2006;6:1. doi:10.1186/1471-2407-6-1

120. Yamada Y, Ikuta Y, Nosaka K, et al. Successful treatment of Cisplatin overdose with plasma exchange. Case Rep Med. 2010;2010:802312. doi:10.1155/2010/802312

121. Emir S, Özyörük D, Arman Ö, Özbek N, Tunç B. Accidental cisplatin overdose in a child: successful management with repetitive plasmapheresis and use of chemoprotective agents. Turk J Pediatr. 2016;58(3):315-317. doi:10.24953/turkjped.2016.03.015

122. Chegini A, Moghadami M, Maghary AH. Therapeutic plasma exchange in Tehran between 2011 and 2014. Ther Apher Dial. 2020;24 (2):230-234. doi:10.1111/1744-9987.12864

123. Mörtzell Henriksson M, Newman E, Witt V, et al. Adverse events in apheresis: an update of the WAA registry data. Transfus Apher Sci. 2016;54 (1):2-15. doi:10.1016/j.transci.2016.01.003 
124. Lu J, Zhang L, Xia C, Tao Y. Complications of therapeutic plasma exchange: a retrospective study of 1201 procedures in 435 children. Medicine (Baltimore). 2019;98(50):e18308. doi:10.1097/MD.0000000000018308

125. Kaplan A. Complications of apheresis. Semin Dial. 2012;25(2):152-158. doi:10.1111/j.1525-139X.2011.01026.x

126. Basic-Jukic N, Kes P, Glavas-Boras S, Brunetta B, Bubic-Filipi L, Puretic Z. Complications of therapeutic plasma exchange: experience with 4857 treatments. Ther Apher Dial. 2005;9(5):391-395. doi:10.1111/j.1744-9987.2005.00319.x

127. Bramlage CP, Schröder K, Bramlage P, et al. Predictors of complications in therapeutic plasma exchange. J Clin Apher. 2009;24(6):225-231. doi:10.1002/jca.20217

128. McLeod BC. Plasma and plasma derivatives in therapeutic plasmapheresis. Transfusion. 2012;52(Suppl 1):38s-44s. doi:10.1111/j.15372995.2012.03623.x

129. Yeh JH, Chen WH, Chiu HC. Complications of double-filtration plasmapheresis. Transfusion. 2004;44(11):1621-1625. doi:10.1111/j.15372995.2004.04154.x

130. Philip J, Sarkar RS, Pathak A. Adverse events associated with apheresis procedures: incidence and relative frequency. Asian J Transfus Sci. 2013;7(1):37-41. doi:10.4103/0973-6247.106730

131. Momtaz M, Fayed A, Marzouk K, Shaker A. Therapeutic plasma exchange outcomes in Cairo university hospitals: 6 years experience. Ther Apher Dial. 2018;22(6):666-673. doi:10.1111/1744-9987.12710

132. Mineshima M, Akiba T. Double filtration plasmapheresis in critical care. Ther Apher Dial. 2002;6(3):180-183. doi:10.1046/j.15260968.2002.00428.x

133. Jouve T, Marlu R, Malvezzi P, et al. Reducing fibrinogen and factor XIII using double-filtration plasmapheresis for antibody-mediated rejection: predictive models. Blood Purif. 2018;46(3):239-245. doi:10.1159/000488928

134. Zöllner S, Pablik E, Druml W, Derfler K, Rees A, Biesenbach P. Fibrinogen reduction and bleeding complications in plasma exchange, immunoadsorption and a combination of the two. Blood Purif. 2014;38(2):160-166. doi:10.1159/000367682

135. Oji S, Nomura K. Immunoadsorption in neurological disorders. Transfus Apher Sci. 2017;56(5):671-676. doi:10.1016/j.transci.2017.08.013

136. Koessler J, Kobsar A, Kuhn S, et al. The effect of immunoadsorption with the immusorba TR-350 column on coagulation compared to plasma exchange. Vox Sang. 2015;108(1):46-51. doi:10.1111/vox.12191

137. Shemin D, Briggs D, Greenan M. Complications of therapeutic plasma exchange: a prospective study of 1727 procedures. $J$ Clin Apher. 2007;22(5):270-276. doi:10.1002/jca.20143

\section{Publish your work in this journal}

Cancer Management and Research is an international, peer-reviewed open access journal focusing on cancer research and the optimal use of preventative and integrated treatment interventions to achieve improved outcomes, enhanced survival and quality of life for the cancer patient. The manuscript management system is completely online and includes a very quick and fair peer-review system, which is all easy to use. Visit http://www.dovepress.com/testimonials.php to read real quotes from published authors.

Submit your manuscript here: https://www.dovepress.com/cancer-management-and-research-journal 